\title{
Arte e educação nas escolas do campo: do reconhecimento das tradições à releitura crítica do mundo
}

\author{
Art and education in rural schools: from the recognition of traditions to the critical \\ re-reading of the world
}

\section{Arte y educación en las escuelas del campo: del reconocimiento de las tradiciones a la relectura crítica del mundo}

Elmo de Souza Lima*

\section{Resumo}

Neste trabalho discutimos sobre os projetos de educação do campo construídos numa articulação com os movimentos sociais, associados à formação crítica dos educandos. Trata-se de uma educação que tem a realidade socio-histórica e cultural dos camponeses como ponto de partida no processo de produção do conhecimento e na compreensão crítica da realidade, associado ao desvelamento das relações políticas e culturais de dominação instituídas historicamente neste território. A partir dos estudos de Freire $(1985,2005)$, Boal (2005), Barbosa (2002) e Duarte Jr. (1981), destacamos as contribuições da arte-educação na construção de práticas educativas emancipadoras que favoreçam, por um lado, a imersão dos jovens no universo da cultura e das tradições locais, reafirmando identidades e pertencimentos, por outro, uma releitura crítica do mundo, evidenciando as riquezas das experiências e saberes produzidas pelos diferentes grupos sociais, assim como, as contradições e injustiças sociais que permeiam historicamente essa região.

Palavras-chaves: Educação do Campo. Arte-Educação. Transformação Social.

Recebido em 03/10/2017 - Aprovado em 21/09/2018

http://dx.doi.org/10.5335/rep.v27i2.11443

* Doutor em Educação pela Universidade Federal do Piauí, com Doutorado Sanduíche na Università degli Studi di Verona (2014). Professor adjunto do PPGEd da UFPI e coordenador do Núcleo de Estudos, Pesquisas e Extensão em Educação do Campo (NUPECAMPO/UFPI), Brasil. Orcid: http://orcid.org/0000-0002-8102-2062. E-mail: elmolima@gmail.com 


\section{Abstract}

In this work, we discuss about the rural education projects built in an articulation with the social movements, associated with the critical formation of the students. It is an education that has the socio-historical and cultural reality of the rural people as a starting point in the process of knowledge production and in the critical understanding of reality, associated to the unveiling of the political and cultural relations of domination historically stablished in this territory. From the studies of Freire (1985, 2005), Boal (2005), Barbosa (2002) and Duarte Jr. (1981), we highlight the contributions of art-education in the construction of emancipatory educational practices that favor, on one hand, the immersion of young people in the universe of culture and local traditions, reaffirming identities and belongings, and on the other, a critical re-reading of the world, highlighting the potential of experiences and knowledge produced by different social groups, as well as the social contradictions and injustices that historically permeate in this region.

Keywords: Rural education. Art-education. Social transformation

\section{Resumen}

En este trabajo discutimos sobre los proyectos de educación del campo hechos en articulación con los movimientos sociales, relacionados a la formación crítica de los educandos. Se trata de una educación que tiene la realidad socio histórica y cultural de los campesinos como punto de partida en el proceso de producción de conocimiento y en la comprensión crítica de la realidad, asociado al desvelamiento de las relaciones políticas y culturales de dominación instituidas históricamente en este territorio. A partir de los estudios de Freire (1985, 2005), Boal (2005), Barbosa (2002) y Duarte Jr. (1981), destacamos las contribuciones de arte-educación en la construcción de prácticas educativas emancipadoras que favorezcan, por un lado, la inmersión de los jóvenes en el universo de la cultura y de las tradiciones locales, reafirmando identidades y pertenecimientos, por otro, una relectura crítica del mundo, evidenciando la riqueza de las experiencias y saberes producidos por los distintos grupos sociales, así como, las contradicciones e injusticias sociales que permean históricamente esa región.

Palabras clave: Educación del Campo. Arte-Educación. Transformación Social.

\section{Introdução}

O debate sobre a educação do campo se intensificou no Brasil a partir dos anos 2000, com a mobilização dos movimentos sociais e de educadores e pesquisadores comprometidos com uma proposta de educação associada à formação crítica dos jovens. Contrapondo-se ao modelo de educação tradicional, descontextualizado e acrítico, propõe-se uma educação que tenha a realidade socio-histórica e cultural dos camponeses como ponto de partida na produção do conhecimento, associada à compreensão crítica da realidade e ao desvelamento das relações políticas e culturais de dominação instituídas historicamente neste território, que limita o poder de ação e transformação social desses sujeitos.

Se por um lado, há essa preocupação com a formação crítica dos camponeses por meio da construção de conhecimentos que reafirmem seu protagonismo na luta pela transformação social, superando o modelo excludente e injusto que imperou 
historicamente no campo, por outro, busca-se pensar numa escola que esteja em sintonia com os anseios das comunidades, que reconheça os saberes e as práticas culturais construídas pelos grupos sociais, refirmando suas identidades e pertencimentos.

Nessa perspectiva, os projetos de educação do campo precisam estabelecer um diálogo com a cultura camponesa, refletindo sobre os elementos simbólicos que dão significado à vida desses sujeitos, frutos de suas intervenções no mundo. A cultura está associada às relações dialéticas que o ser humano estabelece com a realidade, numa dinâmica de transformação de si e do mundo. Portanto, é parte desse processo de produzir-se enquanto sujeito histórico na relação entre sujeito-mundo, por meio das estratégias de intervenção na natureza para a produção de alternativas sobrevivências.

Para Chauí (2000, p. 295), “[...] a cultura é a maneira pela qual os humanos se humanizam por meio de práticas que criam a existência social, econômica, política, religiosa, intelectual e artística”. Desse modo, um projeto de educação comprometido com a formação humana, baseada no estudo e na reflexão sobre a vida dos educandos, não pode deixar de estabelecer esse diálogo com o universo da cultura.

Por essa razão, o trabalho pedagógico desenvolvido nas escolas do campo deve estabelecer um diálogo permanente com os elementos simbólicos e materiais que compõem esse universo cultural, buscando, pela imersão, compreender o modo como os sujeitos pensam este contexto e reelaboram suas estratégias de ação e de relação com o mundo.

A articulação entre educação e cultura é condição essencial ao desenvolvimento de uma educação do campo comprometida com a transformação social, associada à inserção crítica das crianças e adolescentes na vida da comunidade. Uma educação que favoreça o desvelamento dos códigos simbólicos que dão sentido aos modos de ser e pensar nesse território. Por meio desse processo, os educandos terão a oportunidade de compreender-se e reconhecer-se enquanto membro de um grupo social, reafirmando sua identidade, numa relação com os projetos de sociabilidade construídos coletivamente neste contexto.

Com essa articulação entre educação e cultura, os jovens terão a capacidade de problematizar os valores, crenças e modos de organização política que orientam as práticas sociais no campo, construindo novas estratégias transformação social, referenciadas em parâmetros ético-políticos, associados aos princípios da justiça, solidariedade e sustentabilidade. 
Diante dessas reflexões, propomo-nos a discutir sobre a diversidade sociocultural que permeia o território rural brasileiro, evidenciando a importância do Ensino de Arte na construção de alternativas teórico-metodológicas voltadas à formação crítica dos camponeses, por meio da implementação de projetos educativos que reconheçam e valorizem as experiências artísticas e culturais, construídos pelos povos do campo numa articulação com suas práticas sociais.

\section{0 campo e suas diversidades étnicas e culturais}

Numa análise das comunidades rurais brasileiras, observamos que, apesar dos diversos problemas sociais e econômicos que ainda estão presentes nesse território, nos deparamos com uma grande diversidade cultural, negada e silenciada historicamente, tanto no campo das políticas públicas, quanto pelas políticas educacionais, principalmente aquelas relacionadas com a construção do currículo das escolas.

Os discursos difundidos acerca do campo evidenciam, na maioria das vezes, os aspectos negativos relacionados à pobreza e ao subdesenvolvimento, negando suas riquezas e potencialidades. Contrapondo-se a esses estereótipos, os movimentos sociais vêm denunciando os descasos políticos com a população camponesa, destacando as riquezas econômicas, políticas e culturais do campo, construídas a partir da agricultura familiar, que são ignoradas e/ou invisibilizadas pelos discursos hegemônicos comprometidos com o modelo de desenvolvimento capitalista, pautado no processo de industrialização e no agronegócio.

Diante desse contexto, os debates empreendidos em torno da educação do campo estão voltados à construção estratégias políticas e pedagógicas que possibilitem às crianças e os adolescentes a realização de novas leituras acerca da realidade do campo, compreendendo-o como espaço de produção de vida, de relações sociais e culturais.

$\mathrm{Na}$ visão dos movimentos sociais, o campo precisa ser compreendido como esse espaço de diversidade cultural, política e econômica, em constante processo de construção e reconstrução a partir da ação dos diferentes grupos sociais que compõem o meio rural brasileiro. Caldart (2004, p. 153) alerta que:

O campo tem diferentes sujeitos. São pequenos agricultores, quilombolas, povos indígenas, pescadores, camponeses, assentados, reassentados, ribeirinhos, povos da floresta, caipiras, lavradores, roceiros, sem-terra, agregados, caboclos, meeiros, assalariados rurais e outros grupos mais. 
Esses diferentes grupos sociais que constituem o mundo rural estabelecem relações diversas com a terra e a produção da vida, utilizando-se de distintas estratégias de organização política e social para o desenvolvimento de suas atividades produtivas. Dentre esses grupos, prevalece em grande medida o uso coletivo da terra por meio dos trabalhos familiares e/ou associativos,

[...] permeado por um regime de solidariedade que reflete uma prática diferenciada de uso do solo agriculturável, na criação de animais, no tratamento da natureza, nas manifestações comunitárias, nas tradições religiosas, na arquitetura das casas, nas vestimentas, na culinária, entre outras manifestações [...] (SIMÕES, 2009, p. 31).

Além disso, há também uma diversidade geoambiental que permeia o território rural e reflete fortemente no modo como os camponeses se relacionam com o meio ambiente, na organização das atividades produtivas e, consequentemente, das relações sociais e culturais. Os modos como os sujeitos se organizam e produzem sua sobrevivência no sul do Brasil, são diferentes daqueles adotados no nordeste e norte do país, influenciados principalmente pelas características ambientais, climáticas e das forças produtivas.

Os elementos socioambientais e as alternativas de produção da vida, a partir das atividades econômicas, têm uma influência na forma como esses sujeitos organizam suas práticas culturais. De outro modo, temos ainda as influências políticas e culturais oriundas do processo de colonização e da dominação política e econômica que refletem na maneira como esses povos se organizam e imprimem suas relações simbólicas com o mundo.

Diante desse contexto, observamos que as práticas culturais cultivadas na relação dos sujeitos com o campo têm uma relevância na vida dos camponeses uma vez que norteiam e alimentam seus projetos de vida e fortalecem as lutas em defesa dos direitos, na construção dos sonhos e utopias. As celebrações construídas nas comunidades rurais em torno da religiosidade, das festividades, nos rituais de produção, nos mutirões, dentre outros, ampliam os laços de solidariedade, fraternidade e união entre os grupos locais, bem como renovam as esperanças na luta pela construção de um mundo melhor.

A partir das atividades cotidianas, os camponeses constroem relações diversas com o mundo - permeadas pelas atividades do mundo do trabalho e por tradições culturais - festas, rituais, recheados de cantorias, danças e celebrações que reforçam seus modos de viver, sentir e pensar no mundo. São tradições que dão sentido às suas vidas e reafirmam suas identidades e práticas sociais. Desse modo, a arte 
e a cultura refletem as experiências e os sentimentos construídos pelos povos do campo acerca do mundo e das vivências com este território.

Esse modo de pensar o campo em sua diversidade e especificidade traz outras preocupações com relação à complexidade dos processos sociais, culturais e educativos instituídos nesse contexto, demandando projetos educativos abertos ao diálogo e à troca de experiências e conhecimentos com estes povos e suas organizações sociais. Nesse caso, precisamos compreender que:

Os povos do campo têm uma raiz cultural própria, um jeito de viver e de trabalhar, distinta do mundo urbano, e que inclui diferentes maneiras de ver e de se relacionar com o tempo, o espaço, o meio ambiente, bem como de viver e de organizar a família, a comunidade, o trabalho e a educação. Nos processos que produzem sua existência vão também se produzindo como seres humanos (ARROYO; CALDART; MOLINA, 2004, p. 16).

Com base nessa reflexão, os projetos educativos desenvolvidos nas escolas do campo precisam criar estratégias pedagógicas que favoreçam o diálogo entre os saberes diferentes e práticas, reconhecendo a importância das experiências dos camponeses para a consolidação do processo de luta e construção de uma sociedade democrática. Só teremos uma sociedade efetivamente democrática quando os vários grupos sociais forem reconhecidos enquanto produtores de saberes e culturas, tiverem seus direitos sociais garantidos e suas práticas sociais reconhecidas e incorporadas no contexto das experiências pedagógicas das escolas.

\section{As possibilidades de diálogos entre educação e cultura nas escolas do campo}

Os primeiros movimentos em defesa de uma educação que respeite as diversidades culturais no Brasil iniciaram no começo da década de 1960, com o desenvolvimento de projetos voltados à valorização e à defesa da cultura popular, instituídos pelos Centros Populares de Cultura (CPCs), o Movimento de Educação de Base (MEB) e pelo Movimento de Cultura Popular (MCP), inspirados nos ideais políticos e filosóficos do pensamento freireano.

Na visão de Freire (2005), a valorização da cultura popular é o caminho para o reconhecimento e a afirmação das pessoas enquanto sujeitos históricos e o diálogo entre as diferentes culturas, constituindo-se numa estratégia para se ampliar a visão e a compreensão desses sujeitos acerca do mundo e numa alternativa para a emancipação das classes populares. Na perspectiva freireana, 
[...] a cultura não é só a manifestação artística e intelectual que se expressa no pensamento. A cultura manifesta-se, sobretudo, nos gestos mais simples da vida cotidiana. Cultura é comer de modo diferente, é dar a mão de modo diferente, é relacionar-se com o outro de outro modo. A meu ver, a utilização destes três conceitos - cultura, diferenças, tolerância - é um modo novo de usar velhos conceitos. Cultura para nós, gosto de frisar, são todas as manifestações humanas, inclusive o cotidiano e é no cotidiano que se dá algo essencial: o descobrimento da diferença (FAUNDEZ; FREIRE, 1985, p. 34).

Segundo Brandão (2002, p. 45), o projeto de educação popular, instituído a partir do pensamento freireano e das práticas sociais e políticas dos movimentos dos anos 1960, foi um marco na luta contra a educação colonizadora implementada no Brasil, na medida em que reconheceu "na educação brasileira uma cultura alienada, produtora de sucessivas estruturas sociais de dominação e tradutora de sequentes esquemas simbólicos de valores, conhecimentos e princípios de relações sob controle de grupos e classes dominantes [...]".

O diálogo proposto por Freire (1986), entre educação e cultura está associado ao desenvolvimento de práticas educativas que sejam constituídas numa interação constante com as práticas sociais, colocando-se enquanto espaço de trocas de experiências e vivências de novos e velhos conhecimentos. Nessa direção, as experiências de educação precisam adentrar-se no universo sociocultural dos educandos, reafirmando-se enquanto prática cultural. Isso porque, para o autor,

Todos os produtos que resultam da atividade do homem [e das mulheres], todo o conjunto de suas obras, materiais ou espirituais, por serem produtos humanos que se desprendem do homem [e das mulheres], voltam-se para ele [ela] e o [a] marcam, impondo-lhe formas de ser e de se comportar também culturais. Sob este aspecto, evidentemente, a maneira de andar, de falar, de cumprimentar, de se vestir, os gestos são culturais. Cultural também é a visão que tem ou estão tendo os homens [e as mulheres] da sua própria cultura, da sua realidade (FREIRE, 1986, p. 57).

Entendemos que a cultura está associada à existência humana, ao processo de criação e recriação do mundo, implicado naquilo que dá sentido à vida dos sujeitos sociais. Nesse caso, discutir processos educativos implicados com as práticas culturais dos sujeitos constitui-se numa condição essencial ao desenvolvimento de processos educativos que, primeiro, tenham os sujeitos como protagonistas da educação e da produção do conhecimento; segundo, que tenha a capacidade de dialogar com os saberes e valores produzidos nesse contexto, possibilitando uma maior apropriação dessa experiência enquanto conhecimento crítico do seu fazer/ agir no mundo, práxis social. Por fim, que assume o compromisso político de produzir conhecimento acerca da realidade como condição necessária ao processo de transformação social. 
Para Freire (1996), é fundamental compreender a importância do diálogo entre as diferentes culturas como forma de tornar as práticas formativas mais ricas com relação à formação humana e crítica, associada à construção de alternativas de democratização da sociedade. Entretanto, os educadores precisam compreender que a construção dessas relações dialógicas entre os diferentes sujeitos nem sempre ocorre de forma pacífica, pois, para Freire (1992, p. 156), esse diálogo:

[...] não se constitui na justaposição de culturas, muito menos no poder exacerbado de uma sobre as outras, mas na liberdade conquistada, no direito assegurado de mover-se cada cultura no respeito uma da outra, correndo risco livremente de ser diferente, sem medo de ser diferente, de ser cada uma "para si", somente como se faz possível crescerem juntas e não experiência da tensão permanente, provocada pelo todo-poderosíssimo de uma sobre as demais, proibidas de ser.

A construção dessas práticas formativas, fundadas no princípio da dialogicidade, exige que os educadores estejam preparados, tanto no campo ético-político, quanto no teórico-metodológico, para mediarem os conflitos e os embates que surgirão desses diálogos interculturais, possibilitando não a unificação das culturas e, muito menos, a negação de sua diversidade, mas a reafirmação de suas diferenças e a compreensão da importância dessa diversidade para a constituição de uma geração que respeite os diferentes modos de ser/estar no/com o mundo, engajando-se na defesa de uma sociedade pluricultural.

Diante desse contexto, o ensino de arte pode oportunizar aos jovens do campo uma leitura crítica de seu contexto socio-histórico e cultural na medida em que se tenham as condições para o reconhecimento e a problematização dos elementos simbólicos que compõem a cultura do campo e suas inter-relações como as práticas sociais.

Os trabalhos educativos desenvolvidos na perspectiva da arte e educação precisam evidenciar a riqueza e a importância dos elementos culturais para a formação da população e no desenvolvimento sociocultural e político da comunidade, desmistificando os discursos hegemônicos, construídos a partir de narrativas colonizadoras, que impõem ou silenciam as práticas culturais distintas daquelas referenciadas no mundo "eurocêntrico" ou "norte-americano" (DUARTE Jr., 1981).

\section{0 ensino da arte como espaço de releitura crítica do mundo}

Os processos educativos construídos por intermédio da arte devem desenvolver no educando a sensibilidade para compreensão e captação dos sentidos e significados atribuídos pelos diferentes grupos sociais às suas manifestações e tradições 
culturais, construídas historicamente na sua relação/interação com o mundo. Os jovens precisam compreender que as tradições e as linguagens culturais são forma de expressão de suas vivências, sentimentos e experiências coletivas, formas de comunicação das suas experiências no mundo.

É fundamental que os profissionais da educação compreendam o papel estratégico da arte e da cultura no desenvolvimento da visão crítica dos educandos acerca da organização política, social e econômica da sociedade. Por meio das tradições culturais e artísticas, os grupos humanos retratam seus modos de vida, de produção e de significação e compreensão do mundo. Esse processo de compreensão e valorização do universo simbólico que permeiam as tradições culturais é importante para a compreensão do modo como os diferentes grupos sociais se produzem na relação no/com o mundo e como esses pensam, atuam e se vem no/com o mundo.

Os projetos de educação do campo comprometidos com a compreensão crítica da realidade e a valorização/reconhecimentos das práticas sociais dos camponeses precisam mergulhar nesse universo artístico e cultural, possibilitando que os educandos busquem, por meio das diferentes linguagens artísticas e culturais, desvelar as formas de pensar-se no mundo destes sujeitos, extraído deste processo "o pensar do próprio povo", como conforme propõe Freire (2015), condição essencial para o desenvolvimento de práticas educativas libertadoras.

Para Freire (2005), os processos de formação crítica precisam partir desse trabalho rigoroso e ético voltado à compreensão do pensar do próprio povo, de desvendar seus modos de compreensão e significação do mundo e das suas relações com o mundo e com os demais seres humanos. É por meio desse diálogo crítico com o pensar do próprio povo que se constroem as estratégias de problematização, visando à superação do conhecimento ingênuo, do pensamento acrítico, para uma compreensão crítica do mundo, o desenvolvimento de uma consciência crítica do mundo, condição fundamental para a emancipação.

Nessa perspectiva, os projetos de arte e educação devem contribuir na imersão dos jovens no universo da cultura e das tradições locais, reforçando esse processo de reprodução e transmissão de conhecimentos, valores e práticas sociais que reafirmam a identidade e o pertencimento do grupo. No entanto, precisam também instigar questionamentos e problematizações acerca dessas práticas culturais, evidenciando contradições e injustiças sociais presentes naquele contexto social e político, favorecendo novas leituras do mundo e da atuação daqueles sujeitos no processo de transformação daquela realidade. 
Dentro desse contexto, o ensino da Arte precisa fomentar nos educando uma releitura da realidade, compreendendo como as diversas linguagens artísticas são utilizadas pelos diferentes grupos sociais como de manifestar suas emoções, sentimentos, angustias e sonhos coletivos, bem como estratégia de ação política em torno das lutas pela garantia dos direitos básicos necessários a uma vida digna no campo.

Por essa razão, as estratégias pedagógicas utilizadas no ensino de arte na educação do campo precisam instigar os educandos a mergulharem no universo cultural e artístico das comunidades rurais como forma de compreender como os diferentes grupos sociais utilizam as linguagens artísticas como meio de dar sentido e significados às suas práticas sociais. Com esse trabalho, não significa que os educadores irão negar aos educandos o direito de apreciar e conhecer o patrimônio artístico e cultural construído historicamente pela humanidade.

Pelo contrário, o ensino de arte desenvolvido numa perspectiva crítica deve criar estratégias teórico-metodológicas que garantam aos jovens a oportunidade de estabelecer relações entre a arte produzida pelos povos do campo, no âmbito da cultura popular, com aquelas construídas historicamente pelos diferentes grupos sociais, possibilitando com isso uma leitura crítica do processo de transformação e evolução da sociedade a partir dos trabalhos artísticos e culturais.

De acordo com os Parâmetros Curriculares Nacionais (PCN) da área de Artes, o conhecimento da arte abre perspectivas para que o educando tenha uma maior compreensão da realidade sociocultural do Brasil, das diversidades culturais e artísticas produzidas pelos vários grupos sociais que compõem o nosso país. Nesse caso, o estudo da arte constitui-se numa oportunidade para que os jovens tenham uma compreensão do contexto local, numa relação com os aspectos sociais, artísticos, culturais e econômicos que constitui a sociedade brasileira (BRASIL, 1998, p. 20).

Ainda com base nos PCNs, o ensino de Arte tem o propósito de levar os educandos a compreenderem a diversidade de valores que orienta, tanto seus modos de pensar e agir, como dos diversos povos que compõe a sociedade, valorizando o que lhe é próprio, bem como, favorecendo o entendimento da riqueza e diversidade sociocultural brasileira (BRASIL, 1998). Com base nessa proposta, as práticas educativas voltadas ao trabalho com a arte-educação precisam instigar o olhar crítico e criativo dos educandos, tornando-os: 
[...] capazes de perceber sua realidade cotidiana mais vivamente, reconhecendo e decodificando formas, sons, gestos, movimentos que estão à sua volta. O exercício de uma percepção crítica das transformações que ocorrem na natureza e na cultura pode criar condições para que os alunos percebam o seu comprometimento na manutenção de uma qualidade de vida melhor (BRASIL, 1998, p. 19).

A partir dessa reflexão, o estudo da arte apresenta-se como um importante instrumento de formação crítica e cidadã, na medida em que faz uma reflexão sobre a contribuição da arte para a compreensão da história da humanidade e das lutas políticas instituídas pelos grupos sociais na implementação de estratégias de desenvolvimento social, políticos e cultural.

Nesse trabalho com a arte na educação do campo, é importante que os educadores procurem construir com os educandos estratégias de mapeamento das linguagens artísticas vivenciadas no campo, buscando evidenciar os potenciais artísticos e culturais da região, bem como criar uma compreensão mais ampla acerca da diversidade e da especificidade das linguagens artísticas desenvolvidas nas diferentes regiões do país, desconstruindo aquela visão hegemônica acerca da arte associada somente ao modelo clássico europeu.

Os projetos educativos desenvolvidos na perspectiva da valorização da arte e da cultura permitem que os diferentes grupos sociais possam reconhecer e reafirmar suas identidades, valorizando as tradições culturais e a própria história dos povos do campo, na medida em que tem a oportunidade de compreender as riquezas e a importância daquelas tradições para a história e a trajetória de constituição daquele grupo social.

Normalmente, são histórias e tradições imbuídas de valores, sentimentos, experiências e modos de vidas que dão sentido aos processos políticos e organizativos dos grupos, bem como com suas relações com o mundo do trabalho e das relações sociais, consolidando práticas de relações sociais e políticas e modos de socialização e sociabilidade, pautadas no respeito aos seres humanos e à natureza, na solidariedade e na cooperação entre os sujeitos. Por essa razão, é fundamental que os educadores e educandos compreendam que:

[...] aprender arte envolve não apenas uma atividade de produção artística pelos alunos, mas também compreender o que fazem e o que os outros fazem, pelo desenvolvimento da percepção estética, no contato com o fenômeno artístico visto como objeto de cultura na história humana e como conjunto de relações. É importante que os alunos compreendam o sentido do fazer artístico, ou seja, entendam que suas experiências de desenhar, cantar, dançar, filmar, videogravar ou dramatizar não são atividades que visam a distraí-los da "seriedade" das outras áreas. Sabe-se que, ao fazer e conhecer arte, o aluno percorre trajetos de aprendizagem que propiciam conhecimentos específicos sobre sua relação com o mundo (BRASIL, 1998, p. 43). 
Diante desse contexto, é fundamental que os educandos tenham a capacidade de reconhecer a riqueza das atividades artísticas desenvolvidas pelos povos do campo como meio de comunicar-se com o mundo e de expressar sua percepção do mundo por meio de pinturas, esculturas, gravuras, músicas, dentre outros objetos construídos para manifestar seus sentimentos, sua compreensão e sua relação com o mundo.

Mergulhar nesse universo artístico-cultural favorece tanto à apropriação das técnicas utilizadas naquelas produções artísticas, quanto à compreensão daqueles sujeitos nas suas relações sociais e políticas, considerando que as atividades artísticas estão imbuídas de sentimentos e manifestação de ideias e valores que os sujeitos produzem acerca da sua vida. Por isso, compreender o universo artístico produzido pela humanidade, requer esse olhar atento para os elementos sociais, políticos e culturais que se configuram como pano de fundo para aquela obra ou atividade artística (BARBOSA, 2002).

Os trabalhos artísticos buscam, em grande medida, expressar as questões vividas pelos seres humanos nos diferentes tempos históricos. Desse modo, as linguagens artísticas são utilizadas para dar eco às angústias do povo, ou seja, buscam retratar "problemas sociais e políticos, de relações humanas, de sonhos, medos, perguntas e inquietações", bem como, buscam documentar "fatos históricos, manifestações culturais particulares”. Por essa razão, um estudo crítico da arte pode contribuir para uma releitura dessa realidade, "propiciando uma aprendizagem alicerçada pelo testemunho vivo de seres humanos que transformaram tais questões em produtos de arte" (BRASIL, 1998, p. 48).

Nesse contexto, Augusto Boal (2005, p. 48) destaca que o trabalho com a arte e a cultura ultrapassa os limites estéticos e se apropria de outros espaços políticos e sociais, constituindo-se numa estratégia de politização, de desvelamento da opressão e injustiças sociais. Por meio da arte, os grupos sociais podem evidenciar seus conflitos, desejos e angústias, oportunizando aos educadores e educando uma compreensão mais ampla dos sentimentos que permeiam os modos de agir e pensar dos sujeitos sociais.

O trabalho com a Arte no contexto da Educação do Campo se institui como um importante instrumento de emancipação social, na medida em que favorece ao grupo a oportunidade de refletir sobre estes elementos sociais, políticos e econômicos que permeiam suas atividades artísticas e culturais, ressignificando seus modos de pensar e atuar no mundo (DUARTE Jr., 1981).

Nessa perspectiva, os projetos de arte e educação não podem limitar-se à construção de coreografias, de peças teatrais, de músicas folclóricas, de desenhos 
e pinturas. Os educadores precisam compreender que as manifestações artístico-culturais são construções históricas, portanto, estabelecem uma intrínseca relação com as lutas políticas e sociais dos grupos sociais, podendo retratar elementos significativos da história da humanidade. Nesse caso, a "Arte não é somente a Música, a Dança, o Cinema, enfim, as artes ditas oficiais, mas são todas as formas de expressão dos sentimentos e emoções concretos do ser humano" (QUEIROZ; NASCIMENTO, 2012, p. 03).

Na visão de Freire (2005), o processo de segregação e/ou negação da cultura popular, em detrimento da valorização de determinados padrões culturais ditos "universais", constituiu-se numa estratégia de dominação política e cultural dos grupos populares, principalmente, os trabalhadores do campo. Diante desse contexto, os projetos educativos desenvolvidos com o intuito de valorizar as experiências políticas e culturais dos povos do campo, bem como, seus conhecimentos e valores, constitui-se numa importante estratégia de emancipação e libertação destes grupos sociais historicamente excluídos.

\section{Considerações finais}

Os projetos de educação do campo trazem como princípio básico a formação crítica e a emancipação dos camponeses. Nesse contexto, o ensino de arte pode potencializar esses projetos educativos desenvolvidos nas escolas do campo, na medida em que, possibilita o reconhecimento e a valorização da cultura e da história desses grupos sociais, reafirmando suas identidades e práticas socioculturais. Essas experiências podem também ampliar as estratégias de emancipação através do processo de problematização acerca dos valores, crenças e ideologias presentes nas atividades artísticas e culturais, favorecendo uma compreensão crítica dos aspectos sócio-histórico daquele contexto.

Com base nas reflexões tecidas neste trabalho, compreendemos as experiências de arte educação oferecem aos educandos um conjunto de oportunidade para o desenvolvimento de conhecimentos técnicos e estéticos, associados ao processo de compreensão crítica do mundo. Além disso, esse trabalho de imersão crítica no contexto socio-histórico e cultural da comunidade, por meio da arte e da cultura, favorece o desenvolvimento da autonomia e criticidade frente às questões sociais presentes no contexto no qual está inserido, reafirmando o papel estratégico da arte na formação crítica dos sujeitos, bem como, enquanto instrumento de transformação social. 
Acreditamos que esse processo de reflexão crítica sobre a cultura do campo possibilita que educadores e educandos redescubram novos valores e novas formas de ver e interpretar o mundo, a partir de ângulo e contextos diferenciados daqueles vistos anteriormente, com base num padrão político e cultural "eurocêntrico", associado à lógica colonizadora. Nesse caso, o ensino de arte pode trazer referenciais de análise da realidade e dos processos históricos e culturais construídos e vivenciados pelos diferentes grupos sociais, ampliando as possibilidades de interpretações de suas práticas sociais e suas experiências artísticas.

Entretanto, esse trabalho de construção de práticas educativas capazes de dialogar com essa diversidade sociocultural que permeiam a realidade do meio rural brasileiro passa, prioritariamente, pelo desenvolvimento de novos processos de formação docente voltados para a formação crítica dos educadores com o intuito de possibilitar a (re)significação dos valores e saberes internalizados por meio das experiências socioculturais, da formação escolar e profissionais que, muitas vezes, as impedem de compreender o trabalho com a diversidade como uma oportunidade para se reconhecer e afirmar as diferenças como um caminho para a construção de uma educação democrática.

\section{Referências}

ARROYO, Miguel. G.; CARDART, Roseli S.; MOLINA, Mônica. C. Por uma educação do campo. Petrópolis - RJ: Vozes, 2004.

BARBOSA, Ana M. Arte-Educação no Brasil. São Paulo: Perspectiva, 2002.

Boal, A. Teatro do oprimido e outras poéticas políticas. Rio de Janeiro: Civilização Brasileira, 2005.

BRANDÃO, Carlos Rodrigues. A educação como cultura. Campinas: Mercado de Letras, 2002.

BRASIL. Secretaria de Educação Fundamental. Parâmetros Curriculares Nacionais: arte. Brasília: MEC/SEF, 1998.

CALDART, R. S. Elementos para Construção do Projeto Político e Pedagógico da Educação do Campo. In: MOLINA, M. C; JESUS, S. M. Contribuições para a construção de um projeto de Educação do Campo. Brasília: Articulação Nacional por uma Educação do Campo, 2004.

CHAUÍ, Marilena. Convite a Filosofia.12. ed. São Paulo: Ática, 2000.

DUARTE J. João Francisco. Fundamentos da Arte na Educação. São Paulo: Cortez, 1981.

FREIRE, Paulo. Pedagogia do oprimido. 17 ed. Rio de Janeiro: Paz \& Terra, 2005.

FREIRE, Paulo. Pedagogia da Autonomia. São Paulo: Paz e Terra, 1996. 
FREIRE, Paulo. Educação e mudança. 11 ed. Rio de Janeiro: Paz e Terra, 1986.

FREIRE, Paulo. FAUNDEZ, A. Por uma Pedagogia da Pergunta. Rio de Janeiro: Paz e Terra, 1985.

LIMA, Elmo de S. Educação e diversidades nas escolas do campo: a construção de práticas educativas interculturais. In: LIMA, Elmo de S.; MELO, Keylla R. A. (org.). Educação do campo: reflexões políticas e teórico-metodológicas. Teresina - PI: EDUFPI, 2016.

LIMA, Elmo de S. Educação do campo, currículo e diversidades culturais. Revista Espaço do Currículo (On-line), v. 06, p. 608-619, 2013.

QUEIROZ, Milena Sodré; NASCIMENTO, Cilene Canda. Arte-educação no contexto das classes multisseriadas na comunidade da Fazenda Timbó em Amargosa-Ba. In: Anais do III Encontro Baiano de Estudos em Cultura (Ebecult). Cachoeira-Bahia: UFRB, 2012.

SIMÕES, Willian. Comunidades Tradicionais de Faxinais e Gestão de Políticas Públicas Educacionais no Estado do Paraná: Compreendendo Territórios e Territorialidades. 133f. Dissertação (Mestrado em Gestão do Território). Universidade Estadual de Ponta Grossa, Ponta Grossa, 2009. 